\title{
Processamento Sísmico 2D: Linha 26-RL-1993 da Bacia do Recôncavo
}

\author{
Clériston Silva Gama, CPGG/IGEO/UFBA, Manoel Gontijo dos Santos, PETROBRAS S.A. e Milton José Porsani \\ CPGG/IGEO/UFBA \& INCT-GP/CNPq/MCTI
}

Copyright 2016, SBGf - Sociedade Brasileira de Geofísica.

Este texto foi preparado para a apresentação no VII Simpósio Brasileiro de Geofísica, Ouro Preto, 25 a 27 de outubro de 2016. Seu conteúdo foi revisado pelo Comitê Técnico do VII SimBGf, mas não necessariamente representa a opinião da SBGf ou de seus associados. É proibida a reprodução total ou parcial deste material para propósitos comerciais sem prévia autorização da SBGf.

\section{Abstract}

The Reconcavo Basin was the first producer basin of hydrocarbons in Brazil and it was the largest oil producer during 4 decades. That basin has its origin related to extensional efforts acted in Gondwana during the Mesozoic period, and has high index of recoverable oil. This paper aims to present the complete processing flow of the seismic line 2D 26-RL-1993 located in the Northeast compartment of the Reconcavo Basin. The processing flow was applied the following steps: geometry, editing, static correction, velocity analysis, normal moveout correction (NMO), stacking, migration as well as several techniques of filtering and amplitude corrections. We show that the filtering methods to increase the signal to noise ration are crucial to obtaining of a seismic section of good quality.

\section{Introdução}

O processamento de dados sísmicos é uma importante e necessária etapa para a indústria do petróleo que tem por objetivo fazer um tratamento de dados, para se alcançar a melhor imagem possível da subsuperfície. Diante disso a fase da interpretação sísmica depende muito da qualidade de um dado e normalmente ele precisa ser bem adquirido e bem processado. Não é suficiente apenas o dado ser bem processado se foi mal adquirido ou o contrário, pois por exemplo se a fonte usada não tem energia suficiente para atingir o alvo em subsuperfície, ou o grau de cobertura for pequeno, ou a aplicação da profundidade correta das fontes for negligenciada; a qualidade do dado sísmico será ruim e mesmo que o processamento de dados sísmicos seja bem feito ele não apresentará bons resultados. São então feitas atenuações de ruídos ou correções de efeitos indesejáveis atreladas ao próprio meio ou a aquisição sísmica. Nos casos em que a geologia da bacia sedimentar for pouco conhecida e/ou a geologia for complexa é muito importante para o processamento sísmico informações auxiliares como: dados de poços, dados gravimétricos e magnéticos e dados coletados no campo, por exemplo. Este trabalho visa mostrar os resultados e as contribuições de todo o processamento sísmico da linha 26-RL-1993 localizada no compartimento Nordeste da Bacia do Recôncavo (Figura 2), disponibilizada ao LAGEP/UFBA (Laboratório de Geofísica de Exploração de Petróleo) pela ANP (Agência Nacional de Petróleo, Gás Natural e Biocombustíveis) para fins de desenvolvimento acadêmico. Para o processamento da linha foi utilizado o software SeisSpace/Promax desenvolvido pela LandmarkHalliburton. Vamos nos ater principalmente a uma apresentação resumida das etapas de processamento e discuti-las conforme aplicação na referida linha sísmica.

\section{Aquisição de dados}

Segundo informações extraídas do relatório do observador (RO), a aquisição do dado foi feita pela empresa PETROBRAS S.A. no ano de 1994 onde foi empregada fonte explosiva do tipo bananas de hidrogel que fornecem grande energia, com peso de cerca de 2,5 a $5 \mathrm{~kg}$ e enterradas entre 1 a $3 \mathrm{~m}$ de profundidade.

O dispositivo utilizado na aquisição foi um lanço bipartido (split-spread) assimétrico com distribuição de afastamentos 2025-50-0-50-4025 metros conforme a Figura 1. Foram utilizados 240 receptores por tiro para a aquisição e feitos 326 tiros com razão de amostragem de $2 \mathrm{~ms}$ correspondendo a um comprimento total para a linha de $13.150 \mathrm{~km}$. O tempo de registro foi de $5 \mathrm{~s}$. A Figura 2 mostra a localização geográfica da linha sísmica $26-\mathrm{RL}$ 1993 na Bacia do Recôncavo.

\begin{tabular}{|c|c|c|c|c|c|c|c|}
\hline LANC̣o (m) & 2025 & & 50 & & 50 & & 402 \\
\hline ESTAÇĂO & 1 & 119 & 120 & 121 & 122 & 123 & 240 \\
\hline N' CANAL & 1 & 119 & 120 & & 121 & 122 & 239 \\
\hline ARRANJO & $\nabla_{25 \mathrm{~m}}$ & $\nabla_{-} \cdots-\gamma$ & & 0 & $\nabla$ & 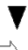 & $\nabla_{25 \mathrm{~m}}$ \\
\hline
\end{tabular}

Figura 1: Parâmetros do arranjo exemplificando as estações para o caso do $1^{\circ}$ tiro.

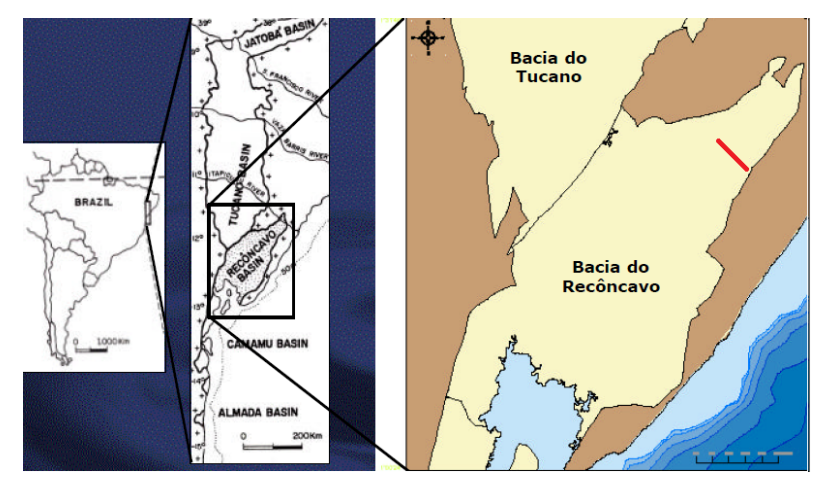

Figura 2: Localização geográfica da linha sísmica 26-RL1993 na Bacia do Recôncavo. Modificada do site Brasil Rounds-ANP. 


\section{Processamento sísmico}

O processamento sísmico da linha foi dividido em duas etapas: o pré-processamento e o processamento avançado. O pré-processamento é a fase dedicada a organização, controle de qualidade, correções de tempo fixo, atenuação de ruídos e/ou identificação de problemas capazes de comprometer a qualidade dos resultados e isso é feito através de passos como a geometria, edição dos dados, correção estática de campo, filtragens e balanceamento de amplitude. Já o processamento avançado emprega técnicas mais complexas e um pouco mais sofisticadas para o tratamento dos dados sísmicos como a análise de velocidade, correção de NMO, correção estática residual, empilhamento, migração, correções de amplitude e filtragens finais. Cada passo tanto do préprocessamento quanto do processamento avançado foi executado no processamento da linha deste trabalho e serão discutidos a seguir.

\section{Pré-processamento}

Feita a conversão para o formato do software onde o dado será processado, segue então a etapa da criação da geometria, onde informações contidas no relatório do observador (RO) e nos arquivos de coordenadas (UKOOA) permitem o georreferenciamento do dado. É nesta etapa que são feitas as amarrações das informações (coordenadas) da (s) fonte (s) e de seus receptores, do espaçamento entre eles, das elevações dos mesmos, do arranjo utilizado bem como o número de tiros dados no levantamento. Essa fase do processamento é primordial e exige bastante atenção do usuário, pois qualquer erro cometido no preenchimento da geometria será replicado em processos posteriores. A geometria nos possibilita organizar e manipular dados em outros domínios tais como: domínio do receptor, do tiro, do CMP, do offset comum; que permitem a execução do processamento de maneira satisfatória.

A fase de edição é um controle de qualidade feito no domínio do tiro para eliminação de traços que possam vir a comprometer os resultados como por exemplo, traços muito ruidosos e com uma baixa razão sinal ruído ou traços com amplitude nula causados por ruídos externos ou problemas e mal funcionamento dos receptores. A eliminação do traço deve ser evitada nos casos em que este contiver informações de amplitudes que podem representar reflexões, então cabe ao usuário julgar quando eliminar um traço ou não a depender de suas condições. É possível substituir traços deletados através de uma interpolação de traços vizinhos dependendo do pacote ou do software que se esteja utilizando no processamento. Nesta etapa é feito o silenciamento ou mute de traços acima das primeiras quebras; refração quando em dado terrestre ou reflexão do fundo do mar quando em dado marinho. É recorrente o uso de silenciamentos ou mutes também em etapas do processamento avançado como na correção de NMO que será citada posteriormente.

Dois tipos de correções de tempo devem ser aplicados aos tempos de reflexão nos traços sísmicos individuais para que esses possam representar corretamente estruturas geológicas em subsuperfície. São elas as correções estáticas e correções dinâmicas, assim chamadas porque a primeira é uma correção aplicada no traço a um tempo fixo enquanto que na segunda varia em função do mesmo. Trataremos aqui das correções estáticas de campo e no processamento avançado as correções estáticas residuais e correção dinâmica. A determinação precisa da correção estática é um dos problemas mais importantes que devem ser resolvidos no processamento sísmico terrestre (Cox,2001).

A correção estática é uma correção de tempo aplicada aos traços sísmicos de maneira que os tempos de reflexão fiquem referenciados a um datum plano. Estas diferenças de tempo são introduzidas por irregularidades próximas à superfície como elevações do terreno, variações da geologia próxima a superfície devido a diferentes graus de intemperismo, aos depósitos superficiais inconsolidados e lateralmente heterogêneos e a variação do nível freático que compõem a camada intemperizada ou Zona de Baixa Velocidade (ZBV). Esta camada pouco consolidada pode ter espessura de até centenas de metros e a velocidade das ondas sísmicas variam de 200 a 1500 $\mathrm{m} / \mathrm{s}$. Esta zona, por essas propriedades, causa uma forte atenuação na propagação das ondas sísmicas por ser um meio bastante dispersivo e heterogêneo, produzindo deslocamentos nos tempos de chegada das reflexões mais profundas, que podem deteriorar a qualidade das seções sísmicas, caso não sejam corrigidos, a ponto de comprometer um investimento feito, dificultando por consequência a interpretação dos resultados ou induzindo a interpretações errôneas. Basicamente a correção estática não pode ser desprezada em dados terrestres, e geralmente, não é aplicada a dados marinhos embora duas distorções podem ser passíveis de serem tratadas; como à profundidade da fonte e dos receptores ou efeitos causados pelas variações do nível do mar provocada pelas marés (Rosa 2010).

A aplicação das correções estáticas representa a simulação que seria caso fontes e receptores estivessem sobre uma superfície denominada datum, em pontos acima ou abaixo de suas posições reais, eliminando assim, portanto os deslocamentos produzidos pela variação da topografia e/ou ZBV. Existem as correções estáticas de campo e as correções estáticas residuais, a primeira associada a correções de intemperismo e elevação que mostraremos resultado a seguir e as residuais que possuem a função de corrigir erros não resolvidos na estática de campo; que serão discutidas adiante. Com a finalidade de deixar mais claro o que ocasiona ao traço sísmico a variação da topografia e da ZBV é mostrado na Figura 3 uma explanação. As definições dos datuns para a correção estática é muito importante. O datum flutuante é estimado como sendo um nível de referência que varia suavemente ao longo das linhas sísmicas e o objetivo de ter os dados no datum flutuante é a minimização dos erros estáticos melhorando processos como a análise de velocidade e a correção de NMO. O datum final é normalmente definido com base em uma média das correções estáticas totais dos traços sísmicos que compõem o agrupamento CMP. Para o caso do presente trabalho foi adotado o datum final para a Bacia do Recôncavo como 0 m (nível do mar).

$\mathrm{Na}$ Figura 4 a seguir mostra um gráfico da topografia do terreno, do datum flutuante e do datum final da linha sísmica utilizada neste trabalho. Na Figura 5 é mostrada a comparação de um sismograma sem a aplicação da correção estática e após a aplicação da mesma. 


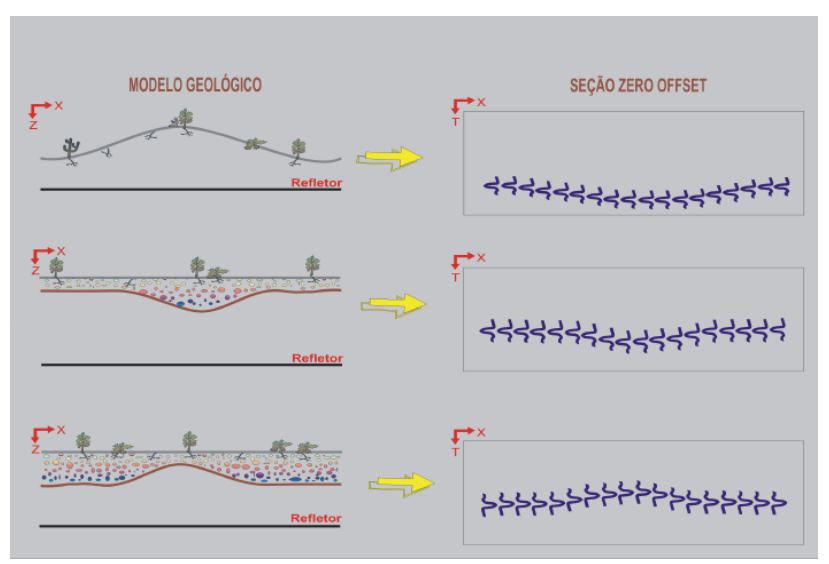

Figura 3: Efeitos da topografia e da ZBV em um refletor horizontal. Extraído de Correções Estáticas (AMORIM e SANTOS, 2007.)

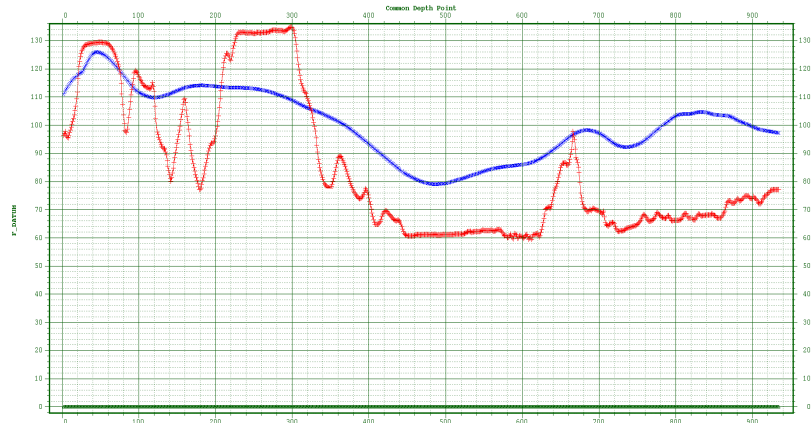

Figura 4: Topografia/elevação da linha sísmica (em vermelho), datum flutuante (em azul) e datum final (em verde).

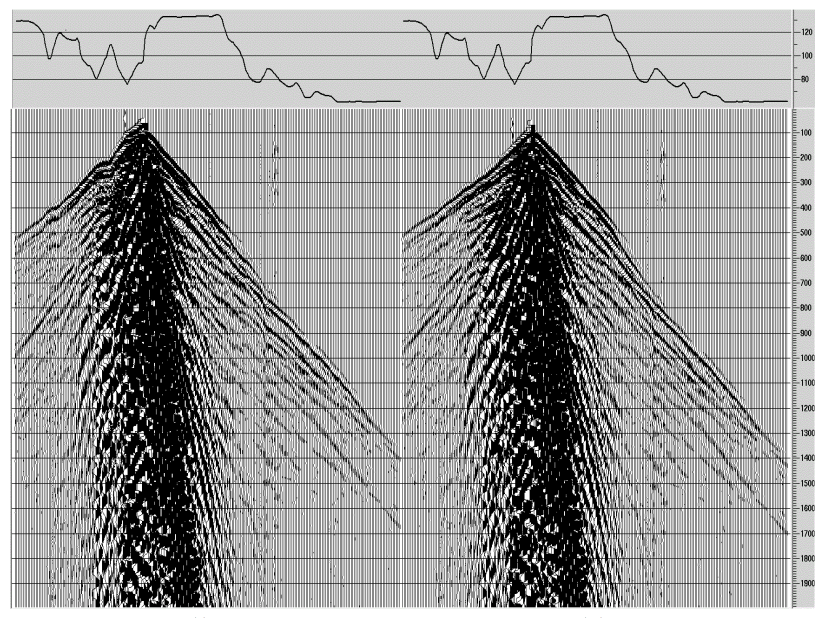

(I)

(II)

Figura 5: Sismogramas antes (I) e após a aplicação da correção estática (II). Acima temos a variação topográfica com sua escala em metros.
Podemos observar que no lado esquerdo do sismograma (I) da Figura 5, onde a topografia varia mais, há um erro maior da estática e, portanto, perceptível em II a sua respectiva correção.

As formas de onda de interesse na geofísica são uma combinação de sinal e ruído. O sinal é a parte de onda relacionada às estruturas geológicas e o ruído todos os outros componentes presentes no registro que não são de interesse. Os ruídos ainda podem ser classificados como aleatórios e coerentes; os aleatórios são geralmente associados a eventos relacionados com as operações de aquisição geofísica como ruídos provocados pelo tráfego de veículos próxima a área do levantamento e os coerentes estão associados própria fonte sísmica como as ondas superficiais geradas por ela.

Dentre desse aspecto quanto mais atenuarmos os ruídos maior será a nossa razão sinal/ruído e, portanto, melhor será a imagem final da subsuperfície. Os dois tipos principais de filtros utilizados são os filtros de frequência e os filtros inversos. No presente trabalho foi utilizado no pré-processamento os filtros inversos como deconvolução spike e balanceamento espectral, já no processamento avançado foi aplicado os filtros de frequência passa banda ou passa faixa (8-12-50-70) e um filtro para atenuação de ruídos aleatórios (Fx Decon).

A deconvolução é um importante passo no processamento de dados sísmicos e frequentemente aplicada para aumentar a resolução temporal ou vertical dos traços sísmicos. O que a deconvolução faz é uma compressão no pulso; transforma um pulso básico em um impulso, desfazendo assim a ação do pulso sobre o traço sísmico e recuperando dessa forma a resposta impulsiva da Terra; removendo efeitos de reverberação no dado. Já a técnica do balanceamento espectral ou branqueamento espectral segundo Yilmaz (1987) é muito boa para atenuação de ruídos de alta energia, logo podemos prever a sua eficácia para um ruído ambiental comum em linhas terrestres como o ground roll que possui alta amplitude e baixa frequência. Apesar de não ser um método de deconvolução o balanceamento espectral pode ser considerado como uma aproximação de uma deconvolução de fase zero pois a sua aplicação altera apenas o espectro de amplitude e não acasiona modificações significativas na fase do sinal (Silva e Porsani, 2006); é uma técnica monocanal que equaliza a amplitude de todos os componentes da fase do sinal dentro da banda de frequência registrada. A Figura 6 abaixo ilustra um sismograma antes da aplicação das técnicas de deconvolução e balanceamento espectral em (I) após a aplicação das mesmas em (II).

As ondas sísmicas ao se propagarem no interior da terra sofrem efeitos que reduzem sua energia e atenuam o sinal (decaimento da amplitude) na qual podemos citar por exemplo: o efeito da absorção, da divergência esférica ou espalhamento geométrico e das perdas de energia por transmissão entre outros efeitos (Abreu, 2005). Devido a isso faz-se necessário a importância de uma etapa conhecida como correção ou balanceamento de amplitudes. Seu objetivo é compensar, dar um ganho ou recuperar amplitudes do sinal e quando necessário atenuar amplitudes que podem vir a ser anômalas. Isto é feito para visualizar melhor as reflexões mais profundas ou até as rasas no caso de serem contaminadas por 


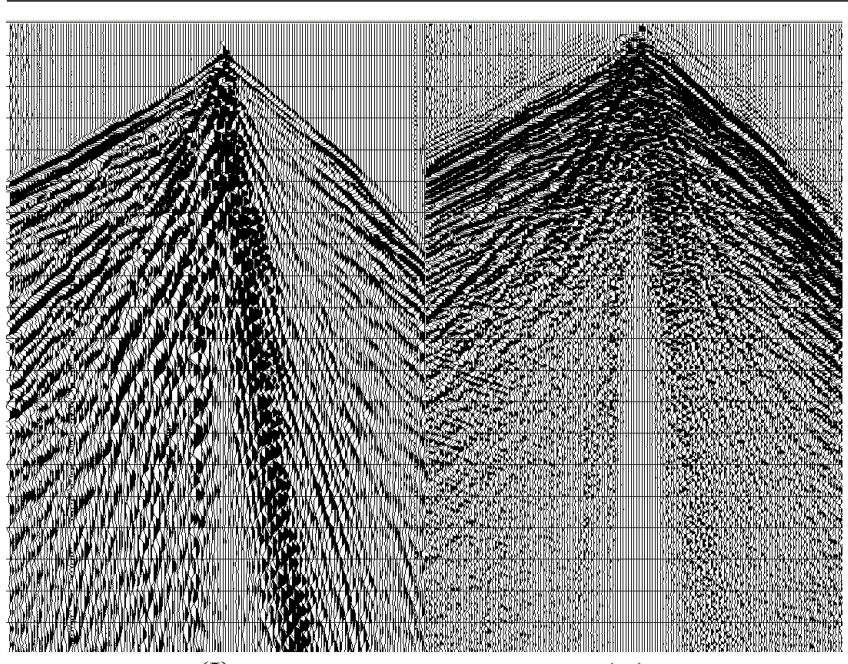

(I)

(II)

Figura 6: Sismograma antes da aplicação dos processos de deconvolução e balanceamento espectral (I) e após a aplicação (II).

amplitudes anômalas.

No presente trabalho foi aplicado uma atenuação de spikes no pré-processamento e no processamento avançado um levantamento e recuperação da amplitude pelo efeito da divergência esférica, através de um módulo que será falado adiante devido a este depender das velocidades nas camadas; e quando necessário ganhos de amplitude nas seções para melhorar a visualização na aplicação de processos e de seus resultados. O método da Atenuação de spikes no pré-processamento foi utlizado para uma atenuação de amplitudes anômalas onde amplitudes que estejam acima da maior amplitude absoluta podem ser zeradas ou não computadas na estatística. É um balanceamento de amplitude bom para se atenuar ruídos não consistentes em superfície e as vezes devido ao seu carácter de aplicação anteriormente citado, funciona também para ruídos que tenham grandes amplitudes como é o caso do ground roll.

É mostrado na Figura 7 a clara contribuição desta etapa que limpou mais o sismograma tanto do cone de ruído do ground roll quanto de amplitudes anômalas aleatórias inclusive em grandes profundidades.

\section{Processamento Avançado}

Como já discutido anteriormente o processamento avançado emprega técnicas um pouco mais sofisticadas para o tratamento dos dados sísmicos. Nessa fase foi aplicado ao dado processado etapas como: a análise de velocidade, a correção de NMO, a correção estática residual, o empilhamento dos dados, a migração, e as correções de amplitude e filtragens finais, que serão discutidas a seguir.

\section{Análise de velocidade}

A análise de velocidade é uma das etapas mais importantes do processamento sísmico, pois essa fase está diretamente ligada ao sucesso do processamento visto que é nela que determinamos as velocidades das camadas em subsuperfície e o grau de precisão alcançado

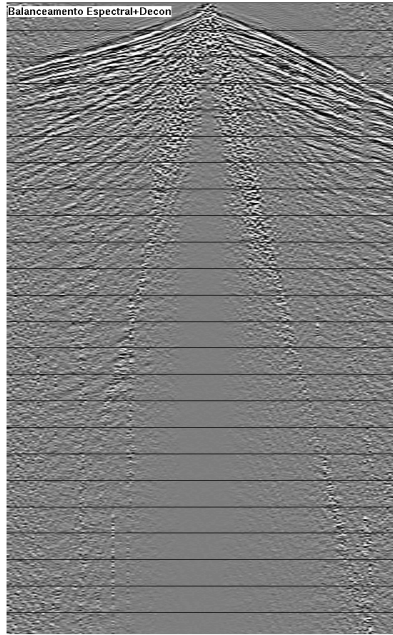

(I)

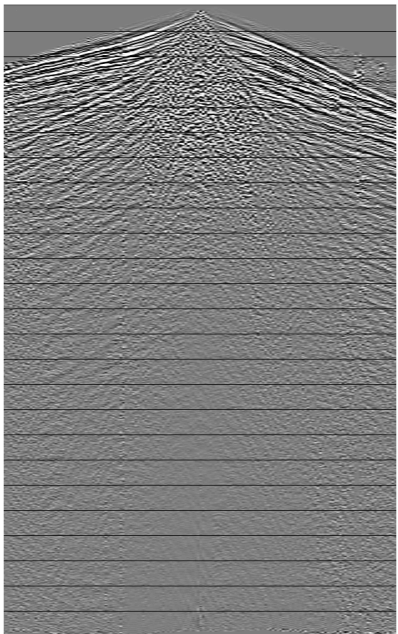

(II)
Figura 7: Mostrando antes da aplicação (I) e após a aplicação da Atenuação de Spikes (II) nos mostrando um sismograma mais limpo de ruídos.

nela determina a qualidade da seção sísmica empilhada e portanto também os produtos posteriores como a seção migrada por exemplo. Nesta fase é feita uma definição das funções-velocidade que melhor compensam as diferenças de sobretempo normal (NMO), das reflexões, ou seja, definir as velocidades que melhor horizontalizam cada reflexão.

Para a determinação das velocidades são marcados os pontos que possuem a maior coerência possível, ou semblance, (região de maior energia), procurando também um trend de velocidades, (tendência de velocidades, orientação geral). Porém ao se marcar ou definir os pontos pelo trend de velocidades, deve-se observar se realmente os refletores foram horizontalizados, pois isso pode variar dependendo de certos ambientes e condições. Na Figura 8 (I) é mostrado um semblance, com pontos interpretados segundo a coerência de regiões com maior energia, e em (II) é mostrada a aplicação da correção de NMO, assunto que será discutido a seguir. A análise de velocidade é uma etapa que deve ser executada mais de uma vez para um refinamento melhor das informações e é comum devido a isso evidenciá-la como análise de velocidade preliminar e análise de velocidade residual, onde ambas foram feitas no presente trabalho.

A partir de uma interpolação linear dos resultados das análises de velocidade dos CDPs avaliados, podemos obter o campo de velocidade RMS, mostrado na figura 9.

\section{Correção de NMO}

A correção de NMO é uma correção dinâmica por assim dizer, devido a ser uma correção que varia em função do tempo de reflexão. É feita para que um mesmo evento esteja em fase para que futuramente se possa empilhar os traços corretamente. Os receptores mais distantes da fonte terão um tempo maior, ou seja, offsets maiores tem um tempo maior de propagação da onda sísmica, então o que a correção de NMO faz é corrigir esses eventos para um mesmo tempo, como se fonte e receptor estivessem no 


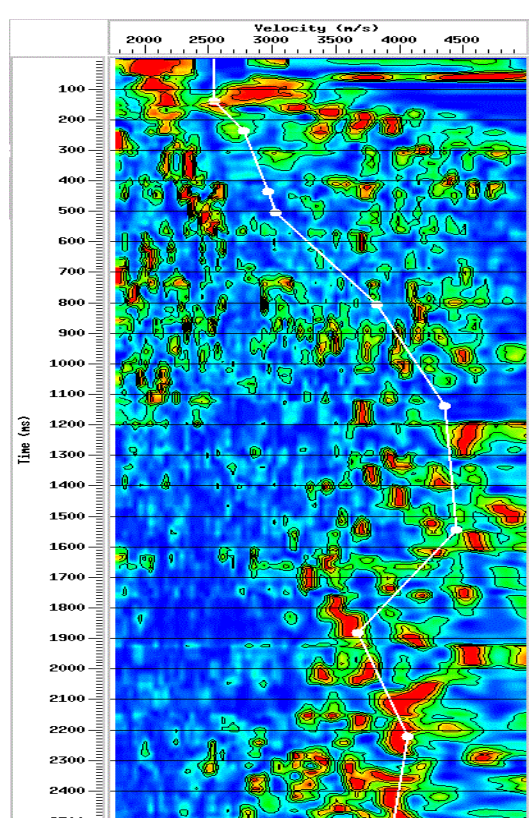

(I)

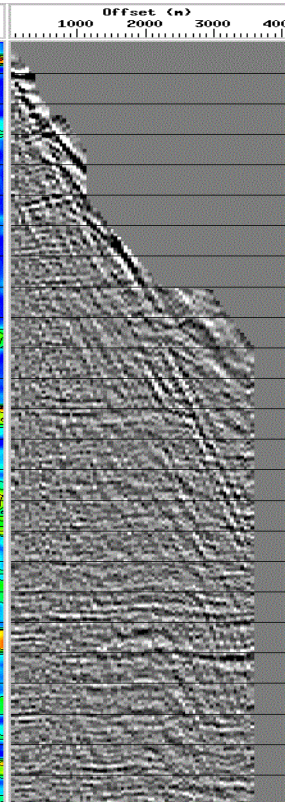

(II)
Figura 8: Análise de velocidade em um CDP qualquer (I). Em (II) vemos a aplicação da correção de NMO, já com aplicação de mute.

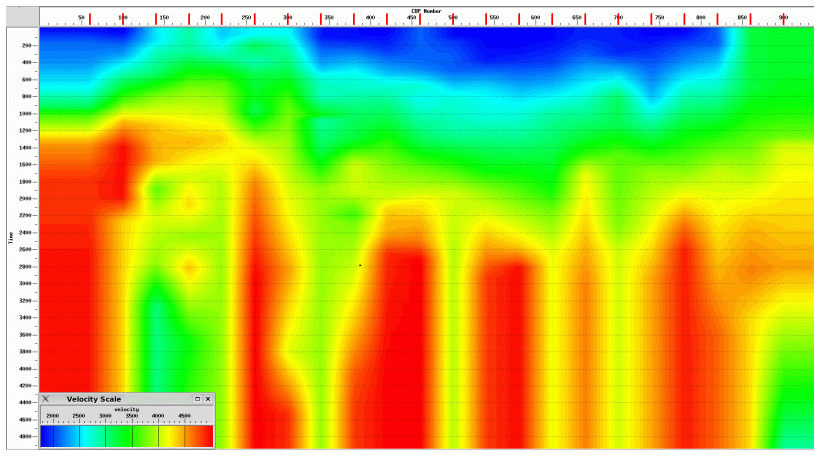

Figura 9: Campo de velocidade gerado através da interpolação dos resultados obtidos na análise de velocidade.

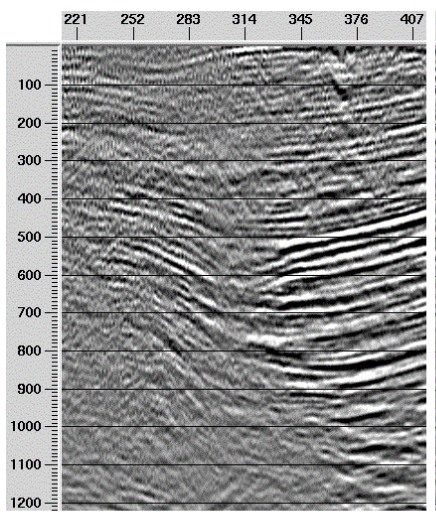

(I)

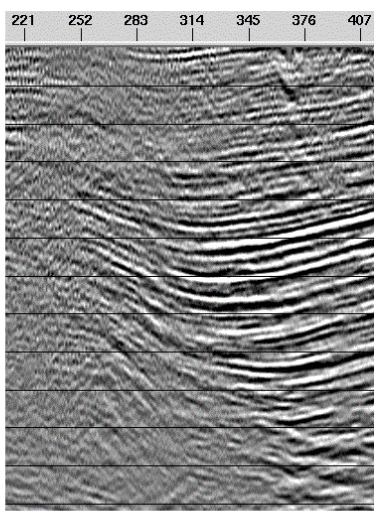

(II)
Figura 10: Corte de uma mesma região comparando, antes da estática residual em (I) e após sua aplicação em (II). mesmo ponto, ou seja, como se o percurso do raio tivesse incidência normal, ou caso de afastamento nulo (zero ofsset). Feita então essa correção podemos empilhar estes dados, após definir um mute ou silenciamento. Pois na correção de $\mathrm{NMO}$, acontece um efeito chamado de estiramento do traço (stretch), ou seja, o traço é esticado devido a ser retirado um tempo o que ocasiona sujeira e um rebaixamento da frequência e quanto maior for o offset maior será esse efeito. Então um mute ou silenciamento, que pode ser automático ou manual deve ser desenhado e executado para minimizar este efeito. Na Figura 8 (II) acima ao lado do espectro de velocidade podemos ver a aplicação da correção de NMO e um mute já executado. No dado processado neste trabalho foi realizada um mute automático e em seguida um manual por cima deste, para se ter uma maior eliminação do efeito de estiramento na seção.

\section{Estática Residual}

Logo após a análise de velocidade e a correção de NMO aplicadas já pode-se calcular a estática residual. O objetivo da correção estática residual é obter um melhor alinhamento possível de sinais primários em traços de uma família CMP. Em qualquer trabalho convencional de correções estáticas residuais, considera-se que os traços sísmicos já tenham sido corrigidos do efeito da estática de campo proveniente das variações das elevações e da ZBV para cada tiro e estação de receptor da linha sísmica.

Resumidamente podemos dizer que a função da correção estática residual é corrigir erros não resolvidos somente com a estática de campo. A consistência superficial significa que os resíduos de tempo dependem exclusivamente das localizações das fontes e dos receptores na superfície. São utilizados, horizontes de referência para a aplicação deste processo de modo a melhorar aos resultados. Podemos ver na Figura 10 um corte apresentando a comparação sem a aplicação da estática residual e com a plicação da mesma, para uma região comum.

\section{Empilhamento}

O empilhamento ou stack é a soma dos traços de uma família CMP após a correção de NMO. Onde todos os traços de cada família CMP são somados resultando em um único traço. Ao final desta fase de processamento já teremos uma primeira imagem da geologia em subsuperfície. Sua qualidade dependerá de uma análise de velocidade corretamente executada. Ao final do empilhamento de traços formam a seção que chamamos de seção empilhada, os CMP's contínuos constituem essa seção sísmica, que é a representação do modelo geológico em subsuperfície. É um processo que melhora as condições de informações obtidas em cada traço devido a redundância de informações ressaltando e mantendo portanto o que é mais coerente e eliminando ou atenuando o que não for. É um processo que funciona como atenuador de ruídos aleatórios, devido ao último princípio citado, que por sua vez aumenta a razão sinal/ruído.

\section{Migração}

A migração é um importante e essencial processo que pode ser aplicado antes do empilhamento (pré-stack) 


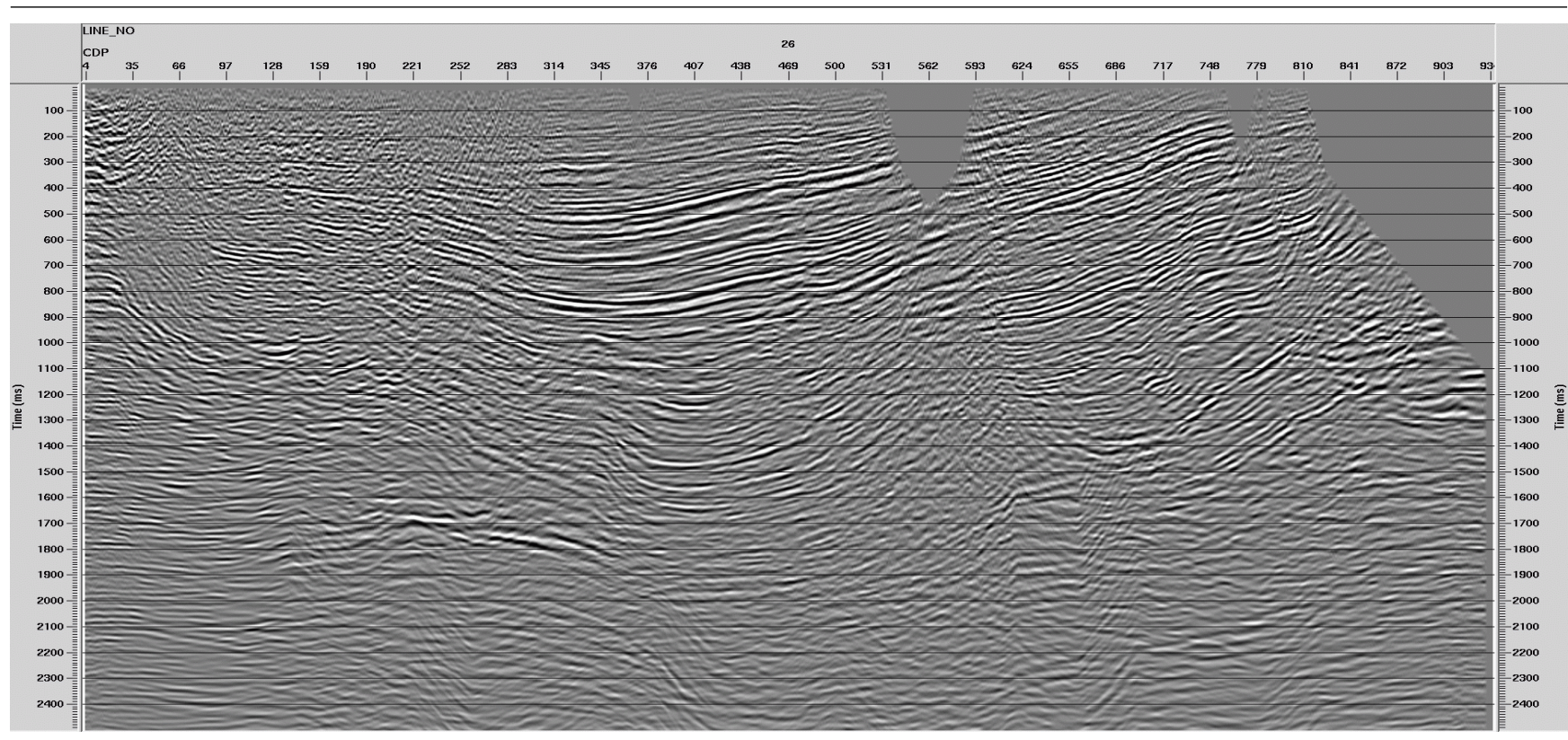

Figura 11: Seção final migrada com correções de amplitude e filtragens finais.

e/ou após o empilhamento (pós-stack). A migração pode ser definida como um método de focalização da energia sísmica pois ela recoloca a energia espalhada na posição do ponto espalhador, normalmente chamado de difrator. É a etapa que corrige os efeitos de mergulho das camadas, movendo-as para suas posições verdadeiras, colapsando as difrações e aumentando assim a resolução espacial da seção. Pode ser também em tempo ou em profundidade e portanto pode ser feita em diferentes etapas do processamento. No presente trabalho foi feito a migração Kirchhoff pré-stack em tempo que pode ser vista na Figura 11.

\section{Conclusões}

O processamento de dados sísmicos é uma etapa de suma importância para a sísmica, principalmente na exploração de hidrocarbonetos que precisam de muitas condições geológicas específicas para sua geração e armazenamento, sem contar das vezes que a geologia é relativamente mais complexa. Um dado sísmico bruto de campo não é capaz de imagear corretamente e claramente a subsuperfície terrestre aplicando puramente uma inversão sem passar por um processamento adequado antes. $O$ processamento realiza edições, manipulações e principalmente correções que a própria aquisição somente não pode, não é capaz ou não é o seu papel de corrigir. Ao longo do tempo, a sísmica recebeu mais e mais investimentos uma vez que permite a melhor aproximação real da geologia em subsuperfície contribuindo e facilitando a interpretação para identificação de possíveis estruturas geológicas que armazenem hidrocarbonetos.

Neste trabalho onde foram mostradas as etapas de processamento da linha 26-RL-1993 da Bacia do Recôncavo, é claro e notório a importância da aplicação de etapas como a edição, correções de tempo, correção de amplitude, filtragens, análises de velocidade, empilhamentos e migrações se aproximaram mais das feições geológicas reais onde deixou mais nítida e limpa de ruídos as seções.

\section{Agradecimentos}

Os autores agradecem ao CNPQ e PETROBRAS pelo apoio ao projeto INCT-GP/CNPq/MCTI. Também agradecemos à LANDMARK- HALLIBURTON pela licença cedida ao CPGG/UFBA do software SeisSpace/Promax e também a ANP pelo fornecimento da linha sísmica. Clériston S. Gama agradece também a bolsa de estudos concedida pelo INCT-GP e ao Geofísico Valdir Andrade Rocha por sua orientação sobre o software utilizado no processamento.

\section{Referências}

ABREU, A .S., 2005. Processamento de Dados Sísmicos do Golfo do México usando o SEISMIC UNIX - Trabalho de Conclusão de Curso, Universidade Federal da Bahia, Instituto de Geociências, Salvador, Brasil.

AMORIM, W. N. DE E SANTOS, M. G., 2007. Correções Estáticas, PETROBRAS, publicação interna.

COX, M., 2001. Static Corrections for Seismic Refeletion Surveys. Society of Exploration Geophysicists - SEG, Tulsa.

ROSA, A.L.R., 2010. Análise do Sinal Sísmico. Sociedade Brasileira de Geofísica, Rio de Janeiro,Brasil.

SILVA, M.G. E PORSANI, M.J., 2006. Aplicação de balanceamento espectral e DMO no processamento sísmico da Bacia do Tacutu. Revista Brasileira de Geofísica., Brasil.

YILMAZ, O., 1987. Seismic Data Analysis: processing, inversion and interpretation of seismic data, Society of Exploration Geophysicists - SEG, Tulsa. 